\title{
Study on the Application of the Bété Script in Modern Graphic Design
}

\author{
Adam Yeo ${ }^{\circledR}$, Fang Cao \\ Department of Design, Nanjing University of the Arts, Nanjing, China \\ Email:yeo_adam2007@yahoo.fr
}

How to cite this paper: Yeo, A., \& Cao, F. (2021). Study on the Application of the Bété Script in Modern Graphic Design. Art and Design Review, 9, 156-179. https://doi.org/10.4236/adr.2021.92014

Received: April 6, 2021

Accepted: May 17, 2021

Published: May 20, 2021

Copyright ( 2021 by author(s) and Scientific Research Publishing Inc. This work is licensed under the Creative Commons Attribution International License (CC BY 4.0).

http://creativecommons.org/licenses/by/4.0/ (c) (i) Open Access

\begin{abstract}
This paper takes the application of the Béte script in modern graphic design as the main content of research; takes the analysis of the Béte script, with their particular expression and connotation, nature and characteristics of the Bété writing system with the approach to revitalizing this Bété script based on the principles of modern typography. The study used both descriptive and experimental methods to produce a sample of graphic works from the Bété script to popularize this writing concept in the culture of graphic design. It introduced a new method of designing fonts of the Béte script based on the criteria of applying the plan. It also explored the use of the Bété scripts in poster design, logo design, and book design. The result of the study indicates that the cultural connotation of the Bété script and the application of the Béte script in graphic design, the basic methods and combined with modern design concepts are reasonable and provide a reference for designers to use this Bété script in graphic design. The result of the study also indicates that the application of the Bété script in these three modes of graphic expression (poster design, logo design, and book design) can enrich modern graphic design while promoting the Bété script and helping to prevent its extinction.
\end{abstract}

\section{Keywords}

Bété Script, Graphic Design, Poster Design, Logo Design, Book Design

\section{Introduction}

While Africa is rich in languages between 200 and 2000 according to the general criteria for distinguishing between languages and dialects (Jaguar, 2011) it is also rich in various sign systems and alphabets. Indeed, while it is true that many languages remain unwritten or that most written African languages use Latin or Arabic alphabets, several writing systems have flourished in several geographical areas in Africa (Kreamer et al., 2007), particularly in West Africa which is a fertile zone for the in- 
vention of new scripts (Dalby 1967, 1968, 1969). But many of these scripts remain little known to this day. This is the case of the Bété script in Côte d'Ivoire.

Writing, as we know, plays an important role in the process of human history and development of human society. It is the product of the unique culture of a people, which is influenced both by their national particularities and by their cultural attributes.

In graphic design, writing and typography have been a major means of communication since the invention of printing (Meggs \& Purvis, 2006). Today, the existence of digital media has pushed typographic design toward formal nature. Thus, we notice the common use in design of scripts such as English, Chinese, French, Arabic, Hebrew etc. However, our strong dependence on foreign languages and our lack of knowledge of African scripts or writing, means that these African scripts are rarely used or even ignored by designers in their creations.

The Bété script, as human writing, has the same properties specific to any writing; that is to say, its main objective is to record things and to express meanings and transmit messages. The Bété script is one of the few scripts in Africa with a unique form of construction; with its own highly conceptualized script, in which each syllable is associated with a relatively fixed meaning and influenced by the Bété culture of Ivory Coast through traditional conceptions. It is because of the specificity of the Bété script in terms of cultural connotations, that its mode of representation in graphic design must also be studied. At same time thanks to the constant evolution of design, with the intensification of cultural exchanges in the world and increasing attention paid to national culture, the characters of the Bété script which contain particular expressions and connotations, could become a design element with strong vitality and cultural characteristics in modern graphic design and enrich this discipline. It is therefore of great importance for research that this article develops a discussion on the use of the Bété script in modern design, to provide designers with a methodological and theoretical basis for the integration of Bété typefaces in modern graphic design while valuing the Bété script.

The objective of this study is finally to make known the Bété script and incite the designers, especially the graphic designers, to use it in their work.

\section{Literature Review}

\subsection{Definition and Origin of the Bété Script}

The Bété script is a syllabary composed of 448 signs, each designating a syllable (448 monosyllabic pictograms to represent phonemes, created in 1952 by the Ivorian artist Bruly Bouabré (1919-2014). ${ }^{1}$ (Figure 1) In 1952, when he went to

${ }^{1}$ Frédéric Bruly Bouabré (deformation of: Gbeuly Gboagbré), born in 1919 in Zépréguhé, circle of Daloa, Ivory Coast. He died on January 8, 2014. Primary studies in Daloa, Dimbroko, and Bingerville (1931-1939). Recruited for the national navy service in West Africa, he landed in Senegal in 1941 and served, until the end of the war, as a sailor in Dakar. He was a railway clerk in Rufisque (1945-1946), then, back in Dakar, he was attached to the judicial identity department until the end of his stay in Senegal in 1957. Two important episodes mark this moment of his life: the "divine vision" of March 11, 1948, following which he created a new religion: "the Order of the Persecuted"; and the invention of African writing. Repatriated to Côte d'Ivoire in 1956, he was assigned to the Ministry of the Interior in Abidjan, then, from 1958 to 1973, to the Directorate of Scientific Research (he "sub-served" at the Ivorian branch of IFAN), and finally, from 1973 to his retirement in 1982, to the Institute of Ethno-sociology of the University of Abidjan. During these last assignments, he wrote abundant scientific work. In 1989, he was finally recognized as a writer (publication of his autobiography, "On ne compte pas les étoiles") and as an artist (participation in the great exhibition "Les magiciens de la terre", in Paris) (Escudier, 2008). 
Békora, a small village in Bété country (in Ivory Coast), where there were a variety of small red and black stones, probably of natural origin but traditionally considered supernatural. These stones come in a variety of shapes and bear "geometric" designs. Bruly studies them, while some of his friends think that his stones are prehistoric money. Bruly Bouabré conclude that they are the remains of ancient writing. He was inspired by geometric figures discovered on the stones and created the Bété alphabet or Bété script. Indeed, the conception of his writing is linked to the resolution of the enigma of these stones that scattered ground of the village Bekorra (the region of Daloa, in the center-west of Ivory Coast). Bruly Bouabré, uses his writing to transcribe tales, texts of the Bété tradition and poems.

The Bété, like the rest of the languages of Ivory Coast, don't have a writing system for their spoken language, so the artist Bruly B. created one and used it, (Figure 2 and Figure 3), along with French, to integrate descriptions of scenes in the composition. His work aims to find a way to fix and transmit knowledge of his people, the Bétés, as well as that of the whole world. He especially "want to preserve the oral Bété culture against inroads of the alien written one" (Michel, 1995). In the introduction to this "Alphabet Bété", he writes:

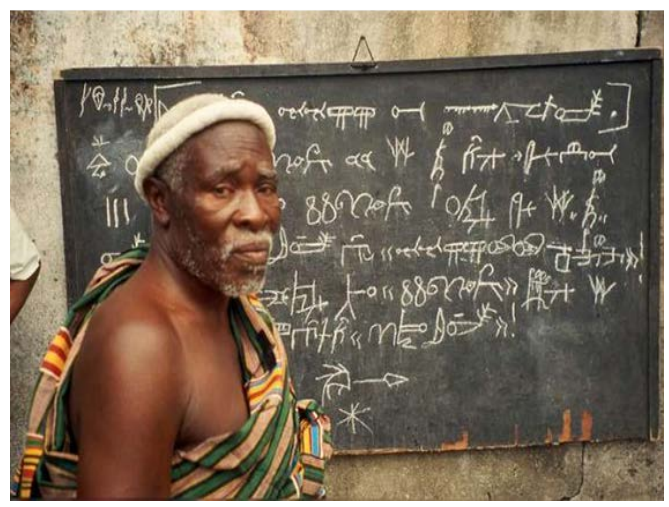

Figure 1. Frederic Bruly Bouabré @ Andé Magnin Courtesy Magnin-A, Paris.

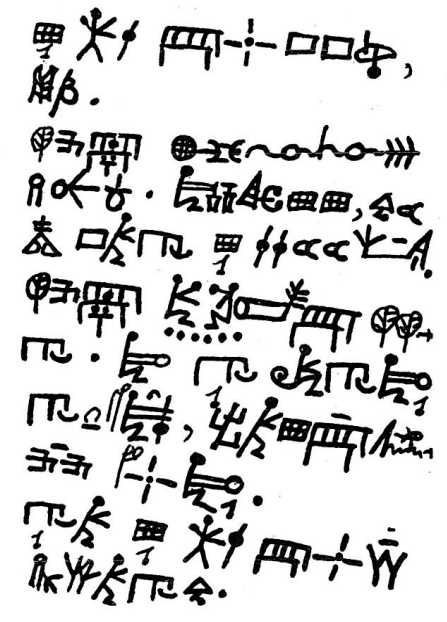

Figure 2. Bété writing. 


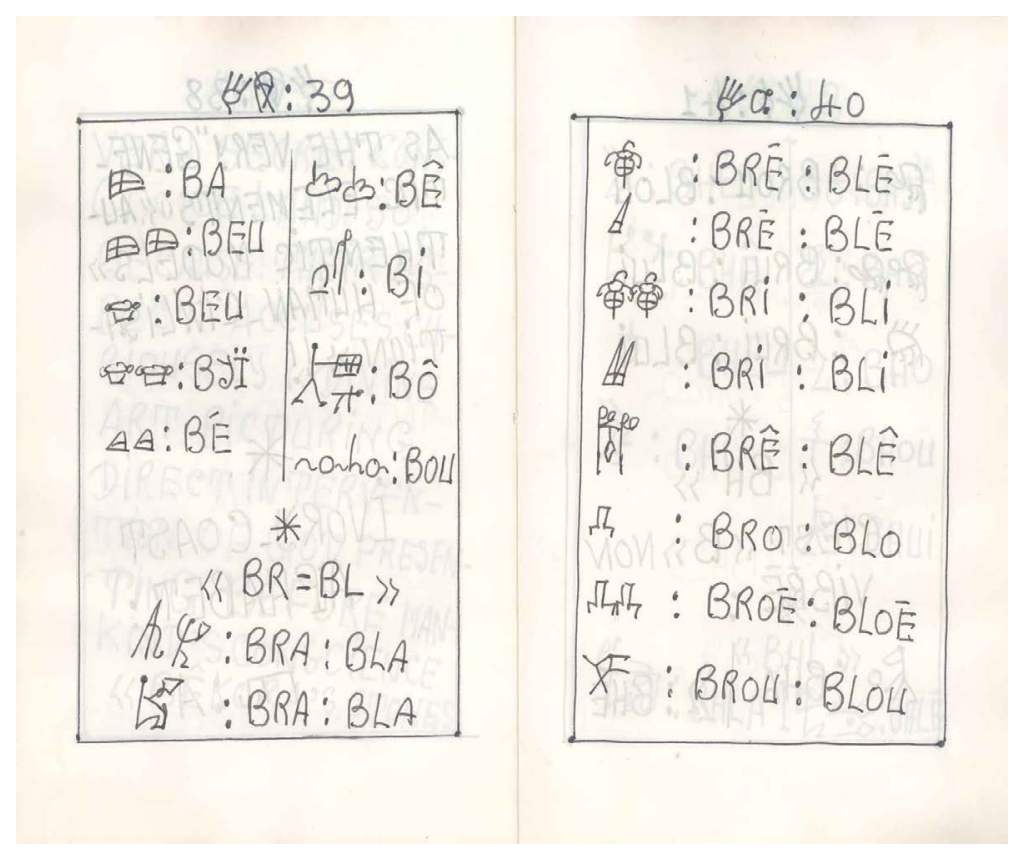

Figure 3. Bété writing Extract from the book: Ouest African Alphabet; The Bété (Bouabré, 1982).

"The alphabet is the undeniable pillar of human language. It is the crucible where man's memory lives. It is a remedy against oblivion, a formidable factor of ignorance" (MAMCO, 2006).

By creating this writing, he wants to rebel and also respond to those who say: "The African did not know writing before European civilization", it is this reflection too often heard, and the author wants to denounce the ignorance or lies of science as disseminated by the colonizer; and it's as we have seen, especially to end with such prejudices (Escudier, 2008).

\subsection{Design Phylosophy of Bété Script}

In Bruly Bouabré's writing system, considered a syllabary, each character represents a syllable, as opposed to a letter or words and phrases. In theory, syllabaries can transcribe any sound that the human mouth makes, making them a viable option for all cultures. This "alphabet" is in some way a "mind game" of using images of things and detached syllables, or portions of words, to express words. This writing is similar to and describes above all practices that go back to 5000 BC: the graphic symbolism derived from Egyptian hieroglyphs, essentially pictographic. This recourse to iconographic signs also marks an element of rupture with the phono centrism of the Latin alphabet. The process is all the more convenient as the Bété language, belonging to the $\mathrm{Krou}^{2}$ language family, has a large corpus of monosyllabic terms that lend themselves well to this exercise. Bruly Bouabré's "alphabet" book is based on logic similar to that of the rebus,

${ }^{2}$ The Krou languages, also called Kroumen languages (in the broad sense), are a branch of the Niger-Congolese language family. They are spoken by nearly 10 million speakers in Côte d'Ivoire and Liberia. https://fr.wikipedia.org/wiki/Langues_krou. 

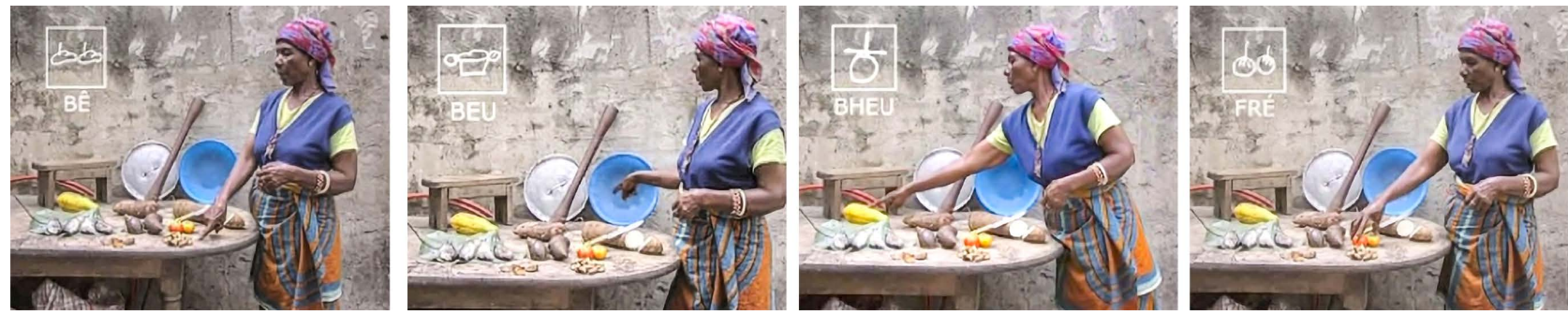

Figure 4. Excerpt from "Bruly Bouabré's Alphabet”, a film by Nurith Aviv, an Icarus Films release. ${ }^{3}$
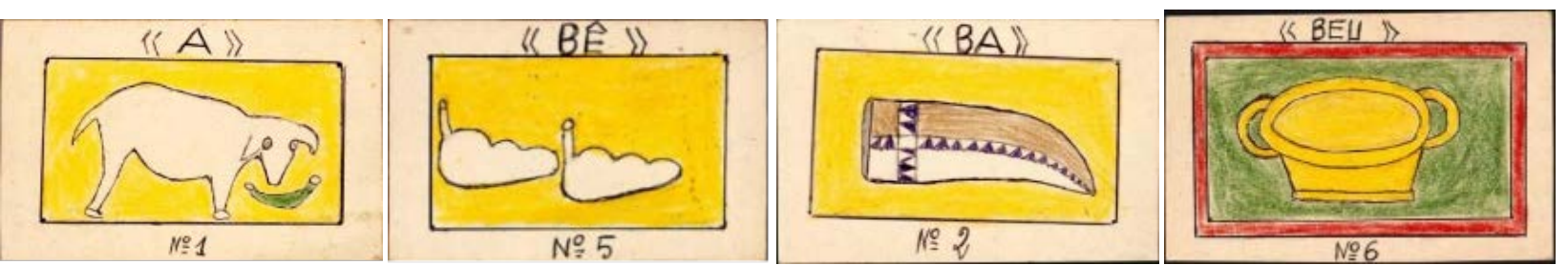

Figure 5. Drawings are part of a series with 448 other works, Alphabet Bété, from CAAC-The Pigozzi Collection. ${ }^{4}$

3Excerpt from "Bruly Bouabré's Alphabet", a film by Nurith Aviv, an Icarus Films release.More info: http://www.icarusfilms.com/if-brul.

${ }^{4}$ Drawing belonging to the Pigozzi collection, visible on the CAAC (Contemporary African Art Collection) website, at the following address (accessed on August 21, 2020):

http://www.caacart.com/pigozzi-artist.php?i=bruly-bouabre-frederic\&m=14\&s=198. 


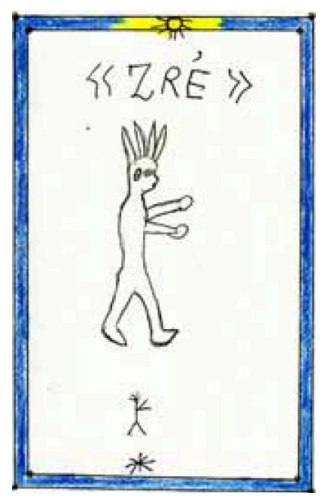

Figure 6. The ideogram ZRÉ: "abbreviated form" (below) And "unabbreviated form" (top).In mythology Bété Zré is a devil with four horns (card drawn on August 15, 2003). Source (Cédric, 2016).
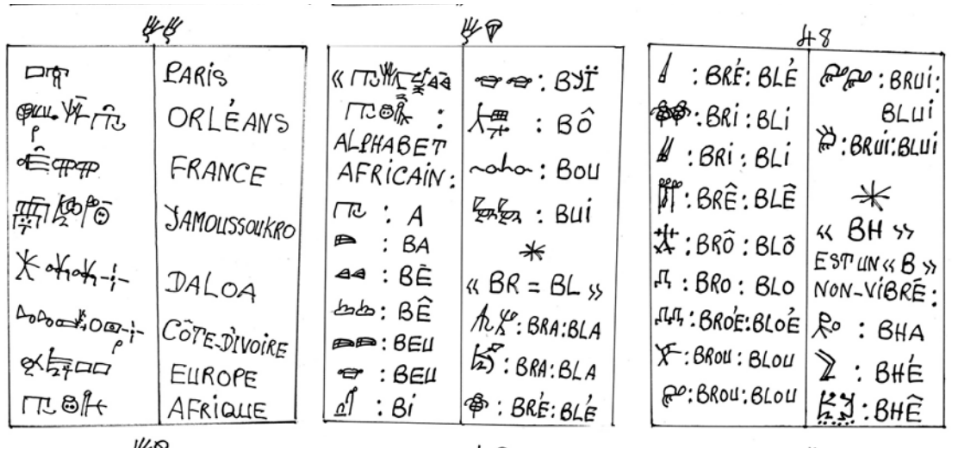

Figure 7. List of places "in double writing" (p.1 \& 43), Beginning of the alphabet book (African Alphaphet”, p.48-49). Source (Cédric, 2016).

Cédric Vincent, reports that:

"Bruly has never ceased to develop his reflection on writing, first by creating his scriptural system, then by repopulating the African past with writing, and then to further extend the scriptural field by investigating so-called natural phenomena. Through drawing, he brings to light a large network of scripto morphic representations that play on the formal similarities and analogies between traces found in nature and characters of Arabic or Chinese writing, when they do not draw on the pictogram. In short, he follows the "scientific" method according which making something visible is proof that it is real. The drawing is designed to render an aspect of reality hitherto invisible. Bruly calls this invisible world the "empire of the dead" (Cédric, 2016).

Note that this writing was born in the context of colonization, at the very moment when African intellectuals were inviting Africans to regenerate and revitalize their traditional cultural values. The creation and dissemination of original African writing is undoubtedly a step in the direction of such a return to the sources. It is undoubtedly a good way to strengthen continental solidarity.

\subsection{Graphic Design and Typography}

Graphic design refers to the formation of a design with artistic, functional, con- 
temporary characteristics and certain scientific and technological content within the framework of two-dimensional space through text, graphics, colors and layout. Text or writing remains one of the important elements of graphic design. One can even say that the process of invention and development of writing is the beginning of graphic design. Graphic design is a design activity that humans developed when they began to use the written word to express and convey information. Besides, an important element of graphic design material is the use of text, its form and layout, being facilitated by typography which is the branch of graphic design that is concerned with how text appears in given space. It is the method by which language is given to visual form. The Swiss typographer Emil Ruder (1914-1942) $)^{5}$, said that typography as a technology "has a simple duty before it and that is to transmit information in writing.

Text and typography have therefore always been inextricably linked to graphic design, both in origin and substance.

To finish this section it should be noted that the Bété script presents particular characteristics (ideographic and phonetic) close to the Egyptian hieroglyphic. It permits to communicate. A common function for all writing. Although it is unknown to many people, this Ivorian script rich in graphics has been known in museums and art galleries around the world through the artistic work of his author. His very particular visual language has interested several contemporary art collectors including Jean Pigozzi in The Jean Pigozzi Collection of African. ${ }^{6}$ His study from the perspective of graphic design (and visual communication) is a first of its kind.And it should encourage more people to learn to read and write this alphabet, to use it in their design projects and to promote it further.

From the point of view of visual communication, art of designing the Bete script could certainly become a very original means of visual communication, particular to the Ivory Coast.

How to use the Bété script in visual communication? This is the question that we will try to answer in the following section.

\section{Research Design}

The research stage aims to analyze the characteristics of artistic expression and the techniques and methods of designing the fonts of the Bété script, (which correspond to "Qualitative Methods (Descriptive Techniques)" in Figure 8. Analyze and interpret by collecting well-known cases as a reference, such as the design of Chinese characters, summarizing these design methods, and their characteristics, (Which correspond to "Analytical Methods + Comparative Methods") in Figure 8 and explore the possibility of implementation of the standard Bété font and its extension into forms of graphic expression, and other artistic design work. (Which correspond to "Applied Method, Experimental

${ }^{5}$ Emil Ruder(1914-1942) Swiss typographer and graphic designer. He taught at the Basel School of Art and was one of those who developed the Swiss style.

${ }^{6}$ The Jean Pigozzi Collection of African Art is a private collection created in 1989 by Italian business man, Jean Pigozzi. It includes several thousand artworks. Art http://www.caacart.com. 


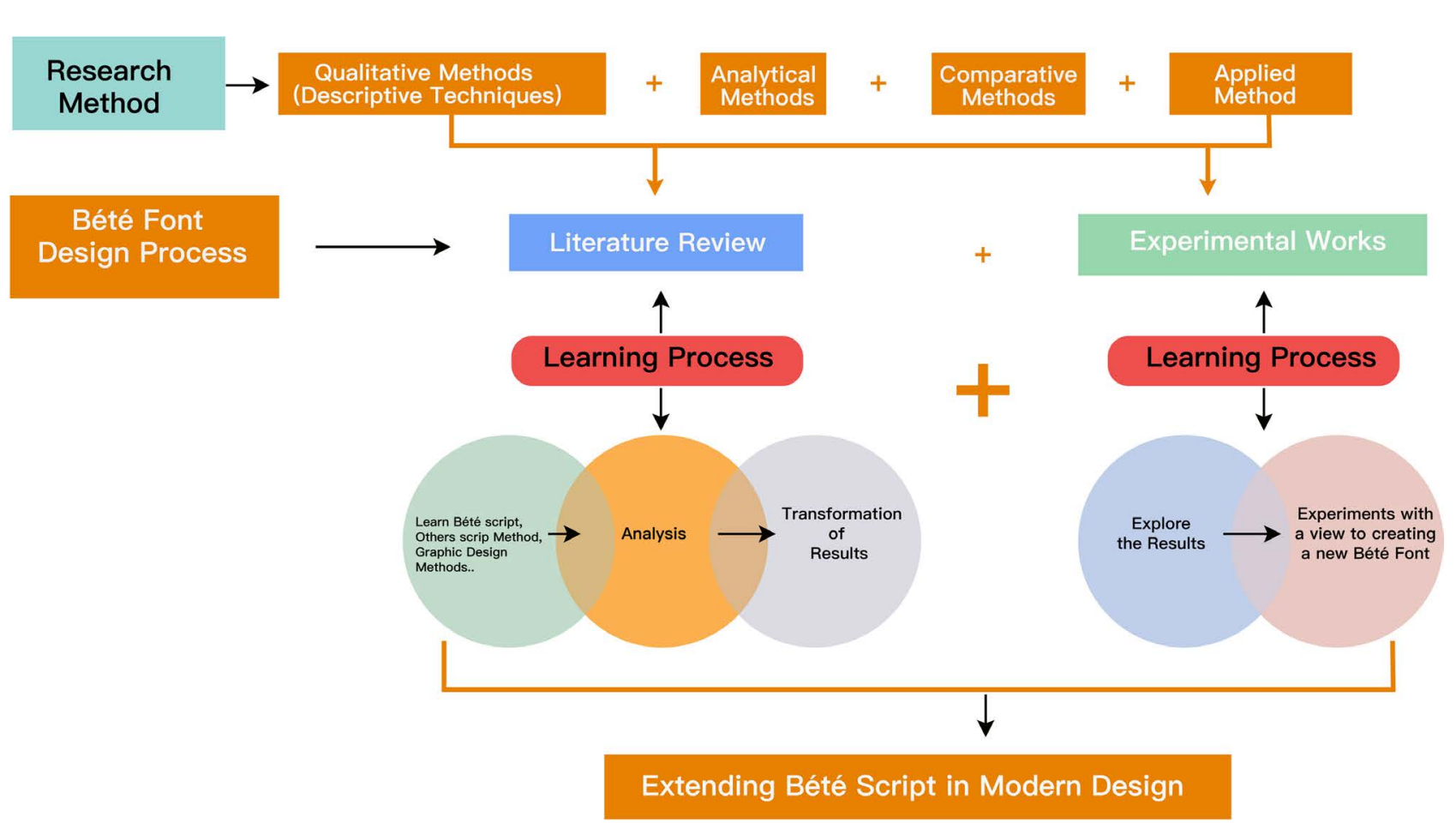

Figure 8. Research framework.

Work...” in Figure 8.

These different research steps are explained in more detail in the next section.

\subsection{Procedure}

As we stated above, we followed research through a design approach. In this respect, our method involved:

1) In the first stage of design, we tried to discover the special characteristics of the Bété script, to bring out the origin, the philosophy behind its creation, and to conduct a comparative analysis to detect the similarities with Chinese characters.

2) Then we tried to feel the inner charm of the Bété font, to imbibe the structure of the font, and to better understand the meaning and value of each font by copying the handwriting several times to learn how to write it. (Figure 9) In summary, this step is to model the pen shape, change the structure, rearrange the pen shape, change the image in the structure, change the relationship between the black and white areas, break the font shape, redraw the structure, etc.

3) Then in this third part, we based on the previous steps and the collected results to apply some known font design the experimental phase aims to analyze the characteristics of artistic expression and the techniques and methods of designing the fonts of the Bete script. Analyze and interpret by collecting well-known cases as a reference, such the design of Chinese characters, summarizing these design methods, and their characteristics, and explore the possibility of implementation of the standard Bété font and its extension into forms of graphic expression, and other artistic design work. 


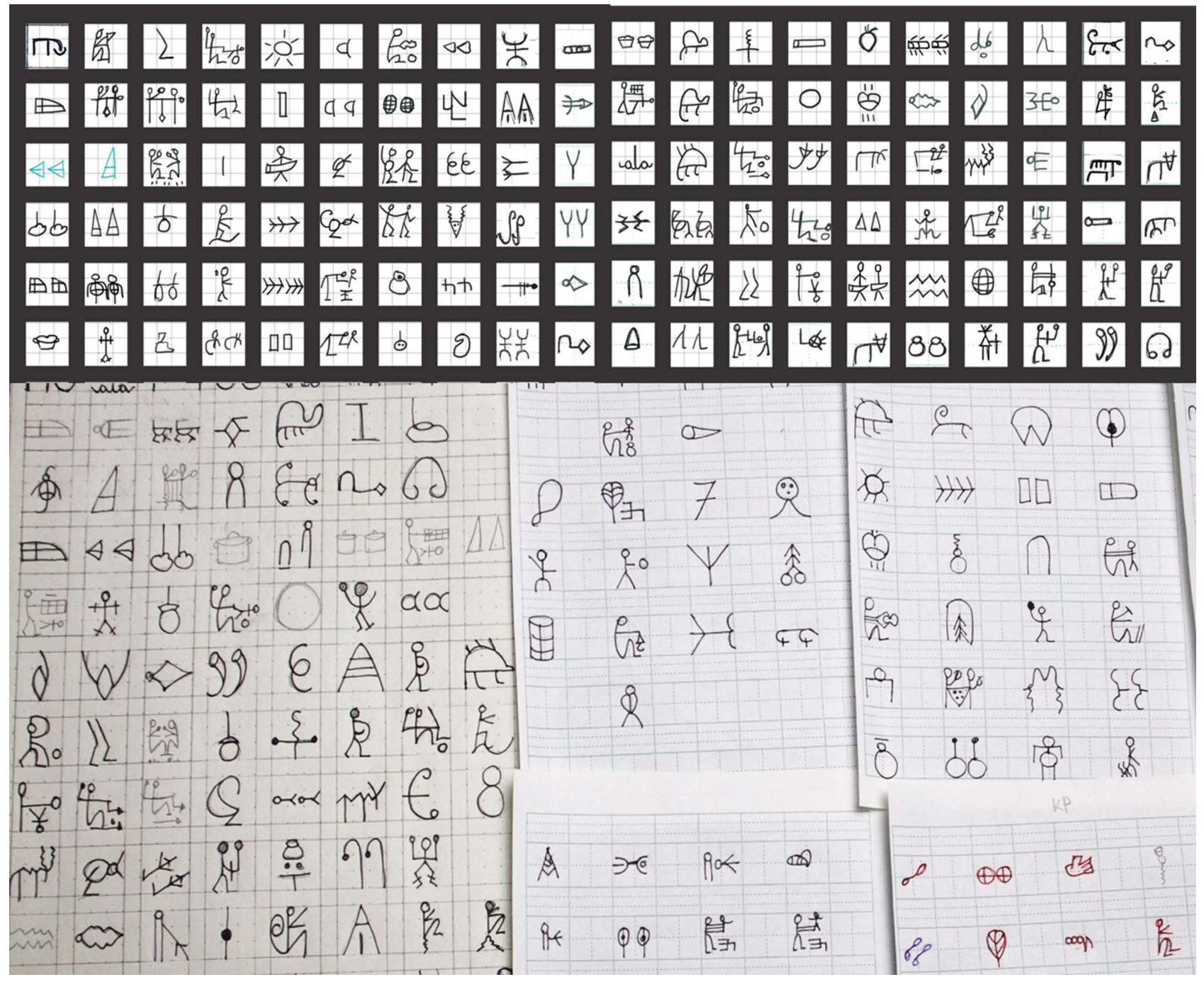

Figure 9. The author's study materials and copied Bété script.

The analysis and summary of modern design methods of Chinese characters and other fonts invented from the design methods of Chinese characters such as Manchu fonts, Mongolian fonts, Dongba fonts, Khitan fonts, etc. allowed us to identify three important characteristics that we will use in the design of Bété fonts: the structure of the font, the reference to the metric design, and the reference to the "six book". That we will see in the following sections.

\subsection{The Structure of Bété Script Characters}

From the morpheme analysis, we found that in font design whether it is Chinese characters or Latin characters, the formation and changes of any font are reflected in the basic stroke form and character structure, and the basic stroke form and character structure are the essential factors of font composition.

We have therefore decided to admit in the font design of the Bété script, a character structure consisting of a square shape or a square grid which will 
therefore constitute the main structure of the Béte font design. This basic structure is similar to the structure of Chinese characters:

"It is internally divided by a grid, which consists of a horizontal line and a vertical line from the center of the square. This structure is commonly referred to in English as the Four-Square Grid (田字格 Tián Zige), and the auxiliary lines that draw the grid are called Centerlines (中心线 Zhōngxīn Xiàn), (Figure 10). The type designer Peiyuan Xie 培元谢 (1936-2000) ${ }^{7}$ created a set of secondary lines called Secondary Centerlines (第二中心线 Di Ėr Zhōngxīn Xiàn) to divide the main grid into eight smaller units (Figure 10). With this method, a second square is delineated in the inner central part of the character, called the Palace Space (中官 Zhōng Guān). A larger palace area can improve the legibility of the symbol or letter of the alphabet as in the case of the Chinese character by reducing the contrast between characters with different stroke numbers" (Guim, 2015).

Whether it is Chinese characters or Latin characters, the formation and changes of any typeface are reflected in the basic stroke form and character structure. The basic stroke form and character structure are the essential factors of typeface composition. The formation of a typographic composition style depends entirely on the basic stroke form of the standardized font.

Besides, any type of font in the combination of pen shape to the standardized structure of the relationship to show the characteristics of the style of the font, the combination of the paraphernalia in the font, the combination of the structure of the individuality of the font to show the image of the style. It is clear from this that the basic form of strokes and character structure is not only the key factor that determines the composition of fonts but also the fundamental source of font creativity.

To sum up, the method of font creation in the Béte script that we have adopted is: shape the form in pen, change the structure, rearrange the form in pen, change the image in the structure, change the relationship between the black and white areas, break the form of the font, redraw the structure, etc.
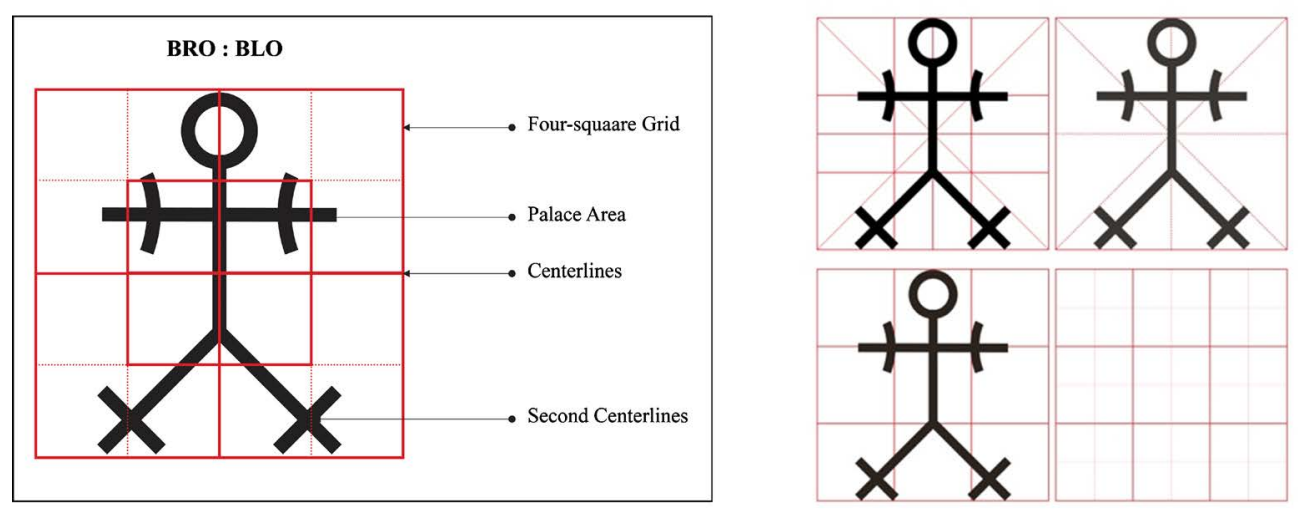

Figure 10. Structure of Bété police characters.

${ }^{7}$ Xie Peiyuan (谢培元; 1936-2000) was a Chinese typeface designer. Xie worked on more than 30 typefaces as a designer or reviser in his life. 


\subsection{Reference to the Concept of "Metric Design" for the Design of Bété Font}

In designing the fonts of the Bété script, we also referred to the concept of "metric design" by Professor Chen Nan', see Figure 11. According to this study developed in his book The Rhyme of Design: A Study in Chinese Characters, (Chen, 2018) following the principles of geometry and typology, the author established a grid matrix of "squares" and "circles", so that the grid of the final design is satisfied with different writing glyphs while taking into account the possibility of satisfying complex and varied characters. In this master grid, both straight and perpendicular lines, oblique lines, and arcs are required, as well as different directions and different size scales. "Metric design": is about innovating and recreating within the rules of the previous design. He asserts that the use of geometric and pictorial principles allows the final design of the grid to be satisfied in different languages. The author put forward the confrontation and fusion of tradition and modernism, between East and West, and proposed the "Metric design" as a design method.

\subsection{Reference to the "Six Books" (六本书) for the Design of Bété Font}

The six books also called the six calligraphies were formed and developed from the end of the Zhou Dynasty $\left(11^{\text {th }}-3^{\text {rd }}\right)$ to the Han Dynasty. The ancients summarized the structure of Chinese characters and analyzed the six methods of character making; these are the six ways of conceiving or writing Chinese words or characters. The principle and form of Chinese characters are fully embodied in this, which offers multiple possibilities for font formatting and creativity.
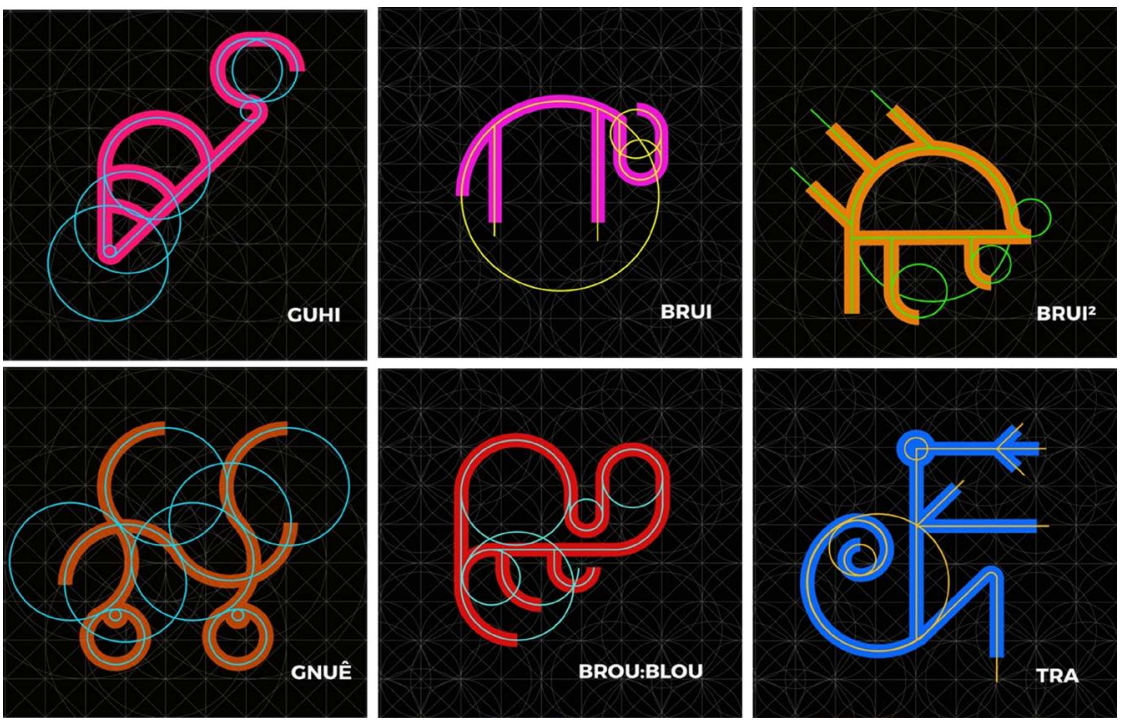

Figure 11. Bété Font design based on "Metric design principles".

${ }^{8} \mathrm{Chen}$ Nan is a professor at the School of Fine Arts, Tsinghua University, His entire research focuses on the application of traditional Chinese culture to modern design, but especially his strong research on Grade Design Theory “格律设计论” and design oracle “设计” (甲骨文). 
Through the interpretation and analysis of the six rules of calligraphy, we can draw inspiration for the creative method of designing Bété fonts.

The six points that make up "the six calligraphies" (Yun, 2000) are the following:

The first one, xiàng xíng "to symbolize the forms", consists of "referring [graphically] to something". In the case of Bete scripts, several syllabaries represent ideograms; " $D \hat{O}$ ", "sun" and " $B$ " $Y$ ", "plate" are part of this type.

The second, xiàng shi "symbolizing things", is "symbolizing a physical form",. In terms of the spellings that symbolize a physical form, the thing is reproduced by drawing along the circumference of the body. This principle is one of the elements on which the author has based himself for the construction of Bété script; each syllable is coded by a referent in the Bété language and represented by a drawing.

The third, xiàng yi "symbolizing ideas", is "indicating form and pronunciation". As for the spellings that indicate the form and pronunciation, one creates a designation (a character) starting from a thing to be represented that is completed by an image (phonetic). In the Bete script (which is mainly phonetic because it uses signs that allow representing sounds from the Béte ethnic group), there are multiple cases; for example, the letter A which comes from the Bete sound $A$; is the sound that is used to chase an animal, for example, a sheep that enters a plot of land and begins to eat things, it is chased by saying " $A$ " see image. The syllabary " $B \hat{E}$ ” which is the sound that designates arachnids in the Bete language.

The fourth, xiàng shēng "symbolize pronunciations", "associates ideas". Concerning [graphy that] "associate ideas," we combine the meaning of the [semantic] categories that one has juxtaposed to show what they indicate. In the Bete script, several syllabaries are of this type. "FOOO", "weapon", and " $F O$ " "confidence", which are almost similar, but different.

The fifth "Zhuan zhü"; "reinterpret". As regards the spellings that reinterpret", a category is established (under which) [the spellings] that have the same meaning are gathered. In the Bete script, some syllabaries adopt two different pronunciations for the same font. This is the case of " $F R \hat{O}$ " "and " $F L O \hat{O}$ " and "FROU" and "FLOU".

The sixth Jiăjiè " borrowing [one spelling for another]"-consists of " borrowing [one spelling for another]". As for the spellings, "borrow [one spelling for another]", at the present stage of the evolution of the Bete script, there are different syllabaries that could be used to represent the same sound to express something similar.

The morphology and structure of the Bété script characters, the design metric concept, as well as the six rules of creation of Chinese characters we have just mentioned, give us a reverential basis that makes the Bete script characters very shapable and creative and brings extremely favorable conditions for the creative design of the Bete characters. The number, form, and proportion of the charac- 
ters of the Béte script became then not static and living adaptable to development of technology and social life, and applicable to many projects of graphic design.

\section{Method of Standardization of Bété Script}

\subsection{Exploration of Standardized Grapheme Patterns Based on Grids}

In our context "Standardisation of Bété" is assimilated to the process to represent, to designing or modeling the Bété script, to make a new form of "standard" written relatively uniform characters, that "standard Bété script can easily be used in the digital age and visual communication projects.

Based on the previous analysis, a sketch of the standardized grapheme model was designed to give 448 "innovative" Bété characters. Based on the cases of the fonts studied and the principles applied in their design, the characters were drawn on design software (AI), and the shape and size of each graphene were conscripted to fit design space, i.e., each character was fitted to the square grid. As shown in Figure 11.

We used a basic square grid with 6 units of size in vertical and 6 units in horizontal. However, the size for the design of the characters varies, from one syllable to another; characters adopt 6 units vertically a number that goes from 2 units to 6 units horizontally, (Figure 12). The design is flexible depending on the length of the characters. In some cases, especially when the syllable is composed of double characters, the font size can be 6 units vertically and 6 to 12 units horizontally (Figure 13). At same time, from the study on the "metric design", the curves, corners, and other curves of the fonts were constructed using a grid of correspondence "square" and "circle", in which there are straight lines and
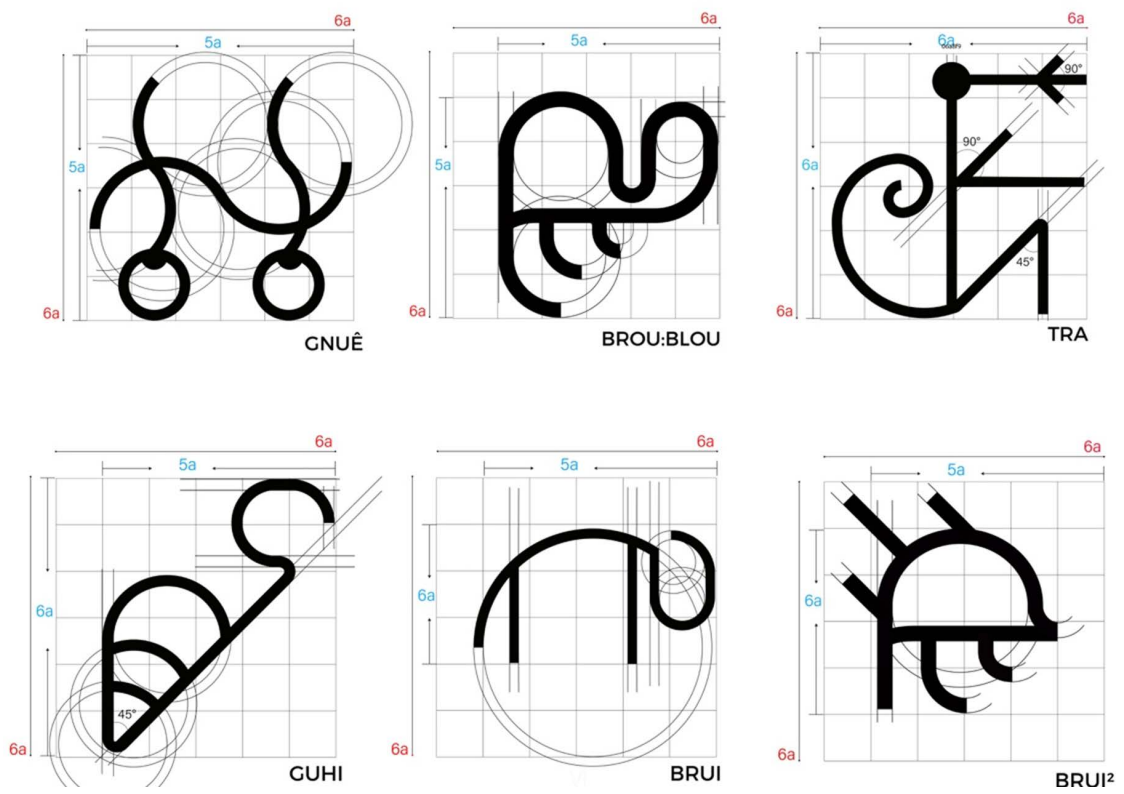

Figure 12. Modelization of full textual element grid. 

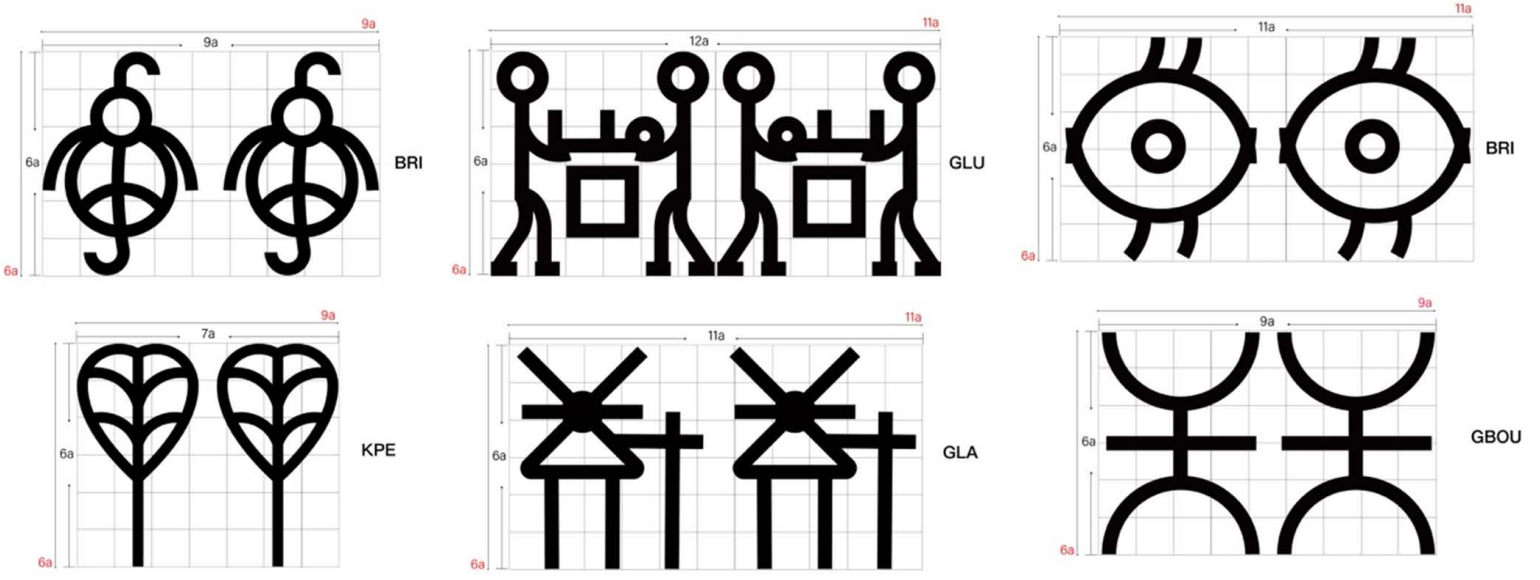

Figure 13. Fonts adopt 6 units in vertical and a number from 6 units to 12 units horizontally.

vertical lines, as well as diagonal lines and arcs. At this stage of the design, the author must constantly adjust and optimize the elements of the design to obtain a satisfactory result concerning the principles of design, and rigorous scientific methods of the grid.

When the final design is standardized. We then tried to design the fonts with different thicknesses of lines, to obtain different visual experiences (Figure 14).

In character design vertical and horizontal lines, diagonals and curves play an important role; indeed, the horizontal line determines width of the font, the vertical line reflects length of the font, while the slanting line is intended to make the font not bound to the boundaries of the box, tauter. Arcs are elements that are not parallel to each other. In the full-text element it is possible to round the corners if you want to create another font style with "rounded corners", this has the impact of also relieving the visual effect of the lines and line a uniform and beautiful visual effect. This is why rounded corners are frequently used in font design.

\subsection{Font Design with Bold Styles}

In any font group, the specification or differentiation of graphemes allows for better composition of letters. The combination of graphemes constitutes letters, and the combination of letters constitutes words. The grid specification method standardizes the skeleton of the graphene, while the thickness of strokes is equivalent to the "flesh" and "blood" of the font, and the combination of strokes of different thicknesses has different visual effects (Figure 15).

We have established the Bété stroke style by matching the thickness of the horizontal strokes and the thickness of the vertical strokes as well as the set of strokes in the font (horizontal, vertical, arc, circle, dot) all must have the same thickness (Figure 15).

As mentioned above, the grid; the skeleton of the grapheme, is the main structure of their font design allowing it to regulate the skeleton of the character elements, for a better font design. 


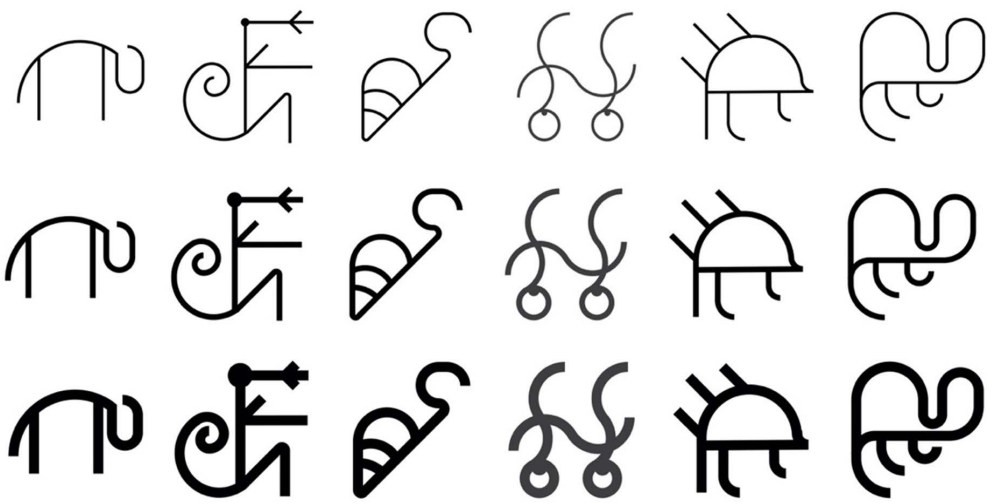

Figure 14. Try to set the effects produced by different thick and strokes.
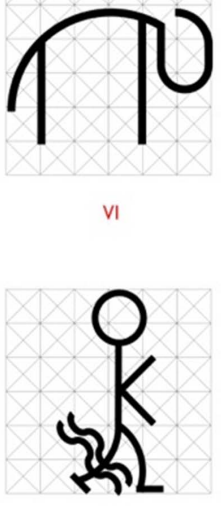

TU

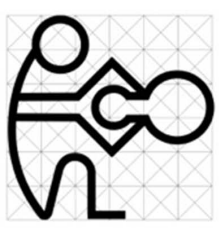

MOU
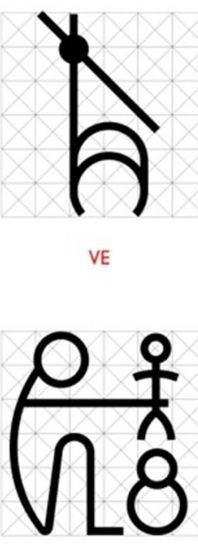

w०

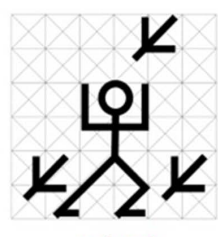

VLOO:VRÓ

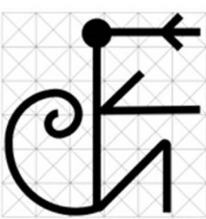

TRA:TLA

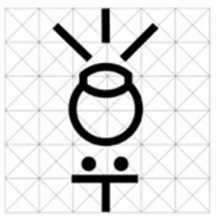

ZLO-ZRO

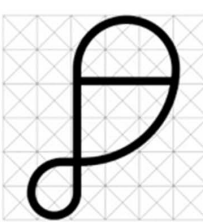

$\mathrm{NI}$

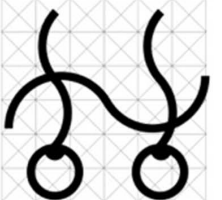

GNUÊ

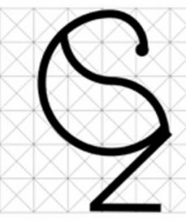

zo

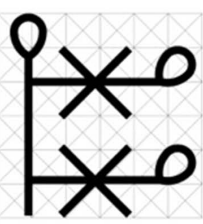

Figure 15. Bété letter forms designed with reference to the bold style.

\subsection{The Combination of the Components of the Bété Font}

In composing the various fonts of the Bété script, we were faced with certain design problems that we tried to solve:

1) Matching the initial Bété characters to the structure of the square grid or matrix, making sure that the stroke shapes fit both straight lines and vertical lines and that the curves, slashes, and arcs, fit the circle and at the same time, different font sizes (Figure 15).

2) Take into account the distance between the graphemes in the square grid, to ensure the visibility of the character (letter) so that the elements of a character are not, neither too big, nor too small. Nor stuck between them.

3) Therefore, in the case of letters composed of double characters of we have enlarged the structure of the grid, going up to 12 units of measure in horizontal 
to ensure the harmony and the good visibility of the whole group of letters.

4) Taking into account the distance between the circled and dotted graphemes and the main graphemes to ensure the visual unity of the letters of the middle line

5) To keep balance with all the fonts, we kept the basic shapes or graphemes which have the same skeleton to facilitate the design of the characters by predisposing these basic shapes, then either converting them again into curves or adding other shapes to create new different fonts (Figure 16). This offers the possibility of decomposing and recomposing strokes to generate new letterforms.

6) Although we have used a standard structure i.e., a square grid for font design, this grid is not unbreakable standards, it can be used flexibly according to the design requirements, it should also take into account the connection of the font elements and respect the principle of harmony between letters.

\subsection{Optimization Stage and Adjustment of the General Form}

The design of the standard Bété font, based on the Bété script characters, given the application of the bété script in the different styles of graphic design, forms a methodical design system, and the final adjustment phase which aims at bringing a general refinement and improvement adjustments for a better visual esthetic. For this reason, in the design of standardized typefaces, the designer must be concerned with the layout, a necessary element that concerns the uniformity of the center of gravity of the typeface and the balance of the visual relationship between the horizontal or vertical composition of the typeface. For example, in various applications (books, newspapers, pictures, maps, etc.), the choice of type size must be carefully considered to ensure good legibility. This is why creative Bété typography can also be applied to a wide range of font sizes.

Finally, it should be noted at this optimization and adjustment stage that the composition of a word in Bété lettering and its visual effect (good or bad) may reflect the shortcomings of the previous stages. Through repeated comparisons and adjustments, we can find more comfortable and esthetically appealing stroke settings without deviating from the original script and losing the sense of the script, etc. After repeated adjustments, we chose the most visually comfortable fonts.

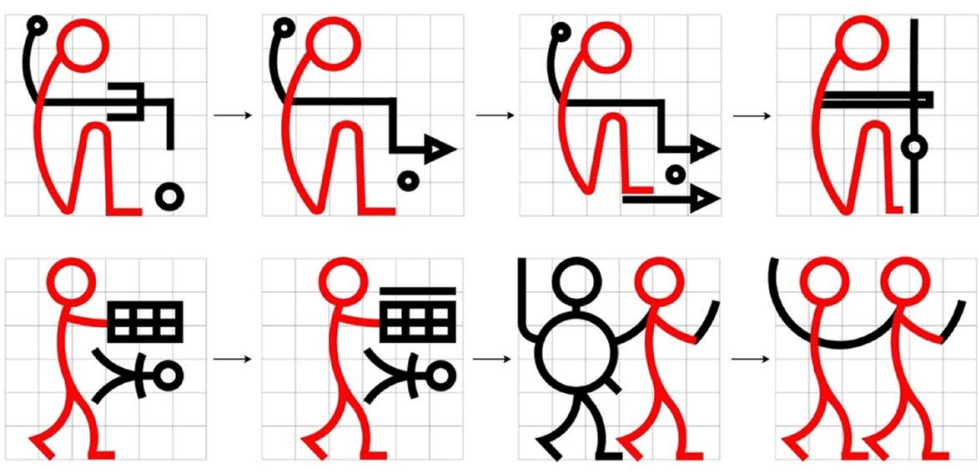

Figure 16. Font design from basic glyphs. 


\section{Results}

The results of this study indicate that the Bété script, which combines the traditional Ivorian thought and esthetic characteristics of the Bété culture of Côte d'Ivoire, has artistic value and inherent visual beauty.

The analysis of modern design methods of Chinese typefaces such as structure, metric design method as well as the six rules of type design and other principles of modern typography, their application to the Bété script has shown that the Bété script typefaces are very shapable and creative, and provide extremely favorable conditions for their application in the three modes of graphic expression (poster design, logo design, and book design.

Indeed, as soon as the rules of font design were applied to the Bété script, the "standard Bété" script was created based on all these rules. That is to say, all the rules of conception design, namely: alignment, contrast, uniformity, the principles of symmetry and asymmetry, rhythm, simplicity, colors... The standardized Bété script, with its characters font (grouping all the variants of a font; with bold, thick, and thin strokes) and with different size, (Figure 17), can now

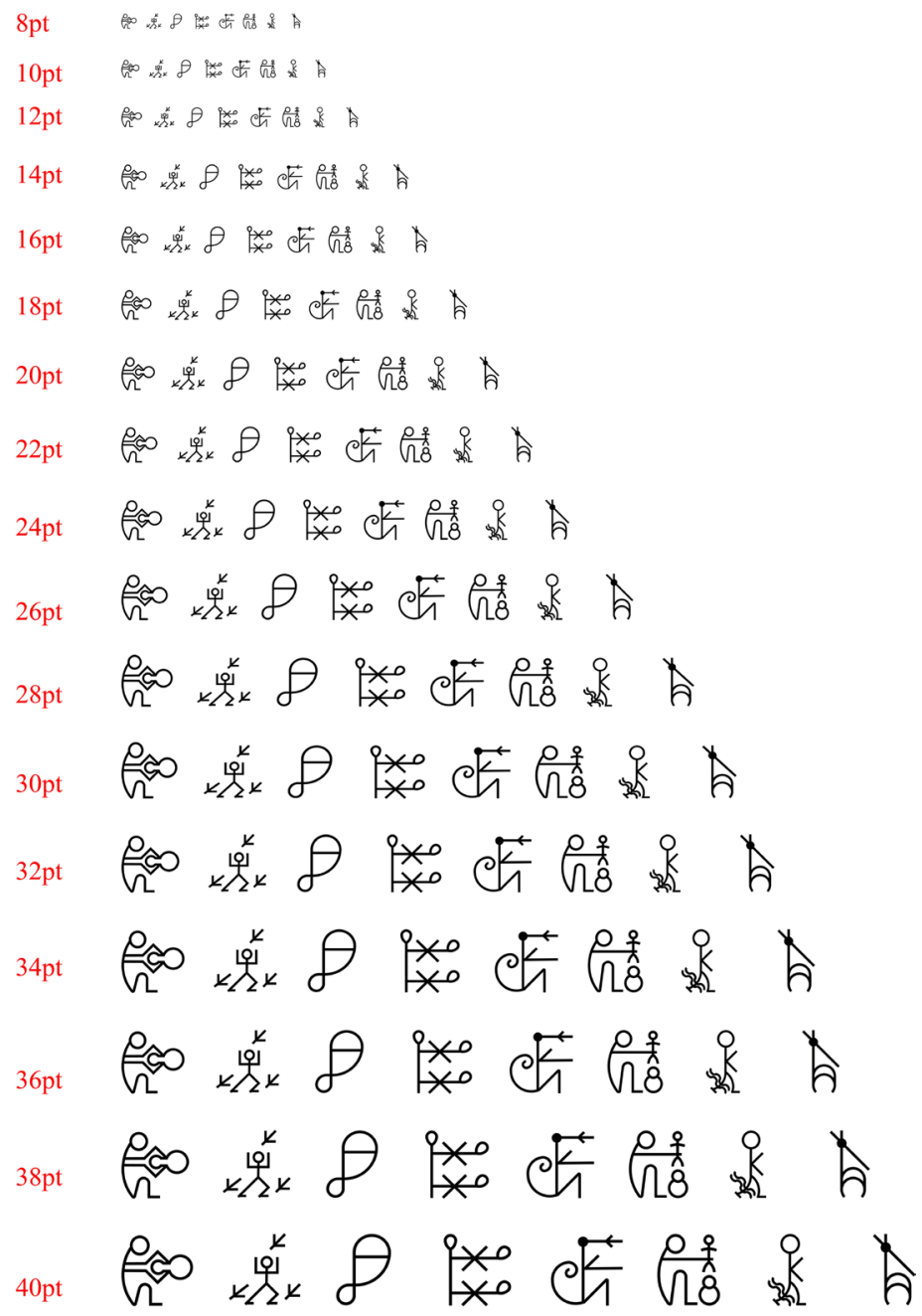

Figure 17. Different Bété font size design. 
constitute modern typography that could be used more easily on different support of visual communication and in different directions of graphic designs. Knowing the importance of typography in graphic design, "Bété typography" can create the most dynamic and creative concepts with the " 448 standardized Bété characters" that we have designed.

The study concluded that the basic methods of typeface design, combined with the specific method of designing the Bété script allow the Bété script to be used in graphic design. These different methods are reasonable and provide a reference for designers to use the Bété script in graphic design (Figure 18).

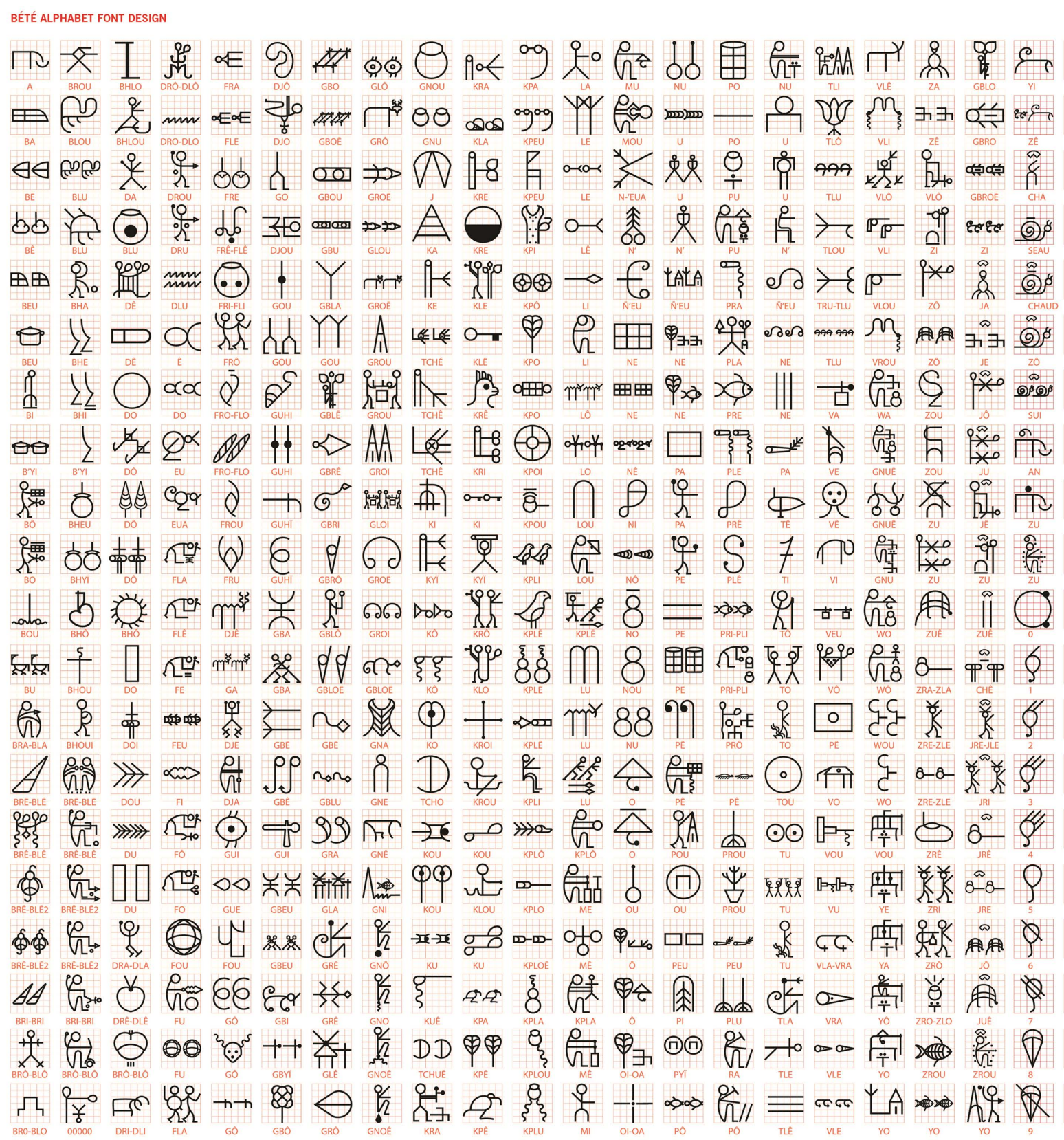

Figure 18. Standardized 448 Bété characters designed by the author 


\section{Discussion}

\subsection{The Application of the Characters of the Bété Script in Poster Design}

The letters and the poster have coinciding parts and are the basis of the poster whose purpose is to transmit information, and the main way of transmitting information is the written word. The Béte scripts as writings also have this prerogative. The use of Bété scripts could also become a means of poster design, with its particular lettering could become one of the most distinctive design elements of modern poster design. Indeed these 448 syllabaries can be arranged in different ways to quickly achieve the role of information flow and information transmission. While showing different visual effects in the poster.

Secondly, the typography of Bété characters is unique and today remains little known. In the design of the poster (its application could arouse curiosity on the part of designers. Because until now we are used to the use of Latin alphabets, Chinese language, Arabic, or Hebrew in the design. This new writing could attract attention. Some others might also use it in their creative projects.

Besides, graphic design is the process of presenting artistic aesthetics, while the Bete characters like Latin, Hebrew, or Chinese letters can become one of the important elements of graphic design, in that it should fully express the ideas of design from the use of forms, structures, phrases and expressions of Béte characters, as well as the coordination of cultural connotations and literal meaning, to promote the integration of written meaning and emotion of design.

In the experimental phase, we designed several posters that we explain in the following lines.

In the first image (Figure 19(a)) the theme of "Humanity " is developed by the integration of image and text written in Béte script that means "HUMANITY" and text in English $S A V E$ with the integration of image and graphics that translate two hands which hold the globe. This poster is an invitation and an interpellation on the need to protect our whole humanity by avoiding actions aiming to destroy our ecosystem.

In the second poster (Figure 19(b)), it is a concrete expression, a concept that the author has created for the transmission and valorization of the Bété script.

The third poster (Figure 19(c)) takes again a thought of the inventor of the script bété; this thought is the following one:

"The love which maintains the fratern ity is the symbol of the terrestrial paradise";

It is an interpellation on the meaning of real friendship, brotherhood and good understanding between human beings. This understanding based on real love is the foundation of a peaceful humanity.

\subsection{The Application of the Bété Script in Logo Design}

In logo design, the Bété characters could be used as a design element. In the process of designing the logo, the designer can also use an image or an abstract 


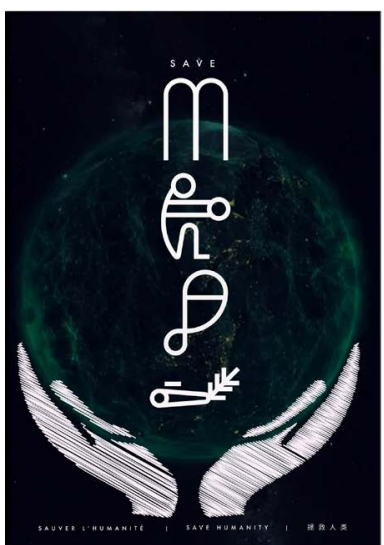

(a)

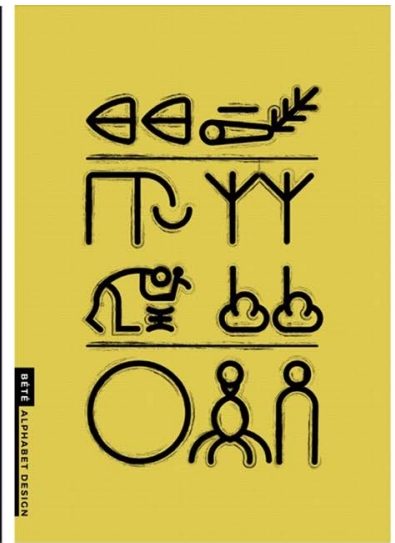

(b)

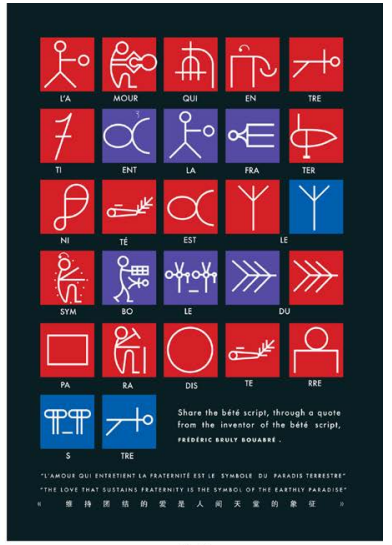

(c)

Figure 19. (from left to right) created by auteur using Bété script

way to deal with the letter Bete; the Bete characters can be pictured to express the characteristics of the logo. To convey that information contained in the logo but also enhance people's awareness of the logo.

The visual memory can also highlight the graphic meaning of the text. That is why we must, in this phase of popularization of the Béte script, associate more often known images to the Bété script in the logo design. In the design, the combination of Bété characters and graphic symbols can also be used to create a new concept, giving a new graphic form based on the original form, This is the case in Figure 20 and Figure 21.

In the design of the logo (Figure 22(c)), we have associated the two syllables " $L A$ " and " $P \hat{E}$ " which are the Bété referents, and which translate the word " $L A$ $P A I X$ " "into French, these two syllables are associated with symbol (a dove) which translates PEACE. To create a different concept without really moving away from the shape of the initial font.

In the logo (Figure 22(b)) it added a graphic symbol that represents "Heart" to express love.

Besides, we can notice that in the logo of good omen realized (Figures 22(a)-(f)) certain modifications were operated on the initial form of the script to give a more attractive result.

Also, to broaden the use of the Bété script in the design of the logo, we can refer to the principles of "six calligraphies or six books": 1) "symbolize the forms"; 2) "symbolize the things"; 3) "symbolize the ideas"; 4) "symbolize the pronunciations"; 5) "reinterpret"; 6) "borrow spelling for another".

\subsection{The Application of the Bété Script in Modern Book Design}

The characters of the Bété scripts are rich graphically and in connotations and can transmit information in a lively way, indeed one of the principal functions of the books is to display textual and internal information with the aim of either telling stories or giving information. The author of Bete script himself since the invention uses his writing to transcribe tales, texts of the Bété tradition, and poems. 
In book design, for example, in the case of bookbinding, the composition of texts is an important element that the designer must pay attention to. Words should be arranged from left to right or top to bottom taking into account the overall context of the layout when designing, including the spacing between
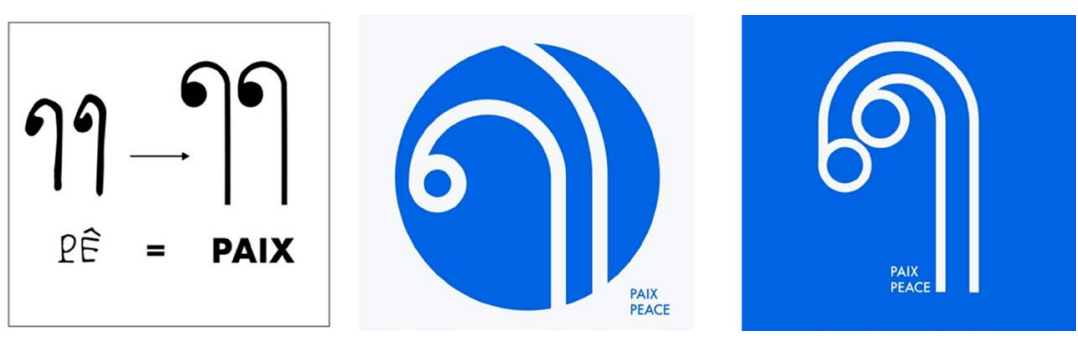

Figure 20. Poster created by auteur expressing PEACE.
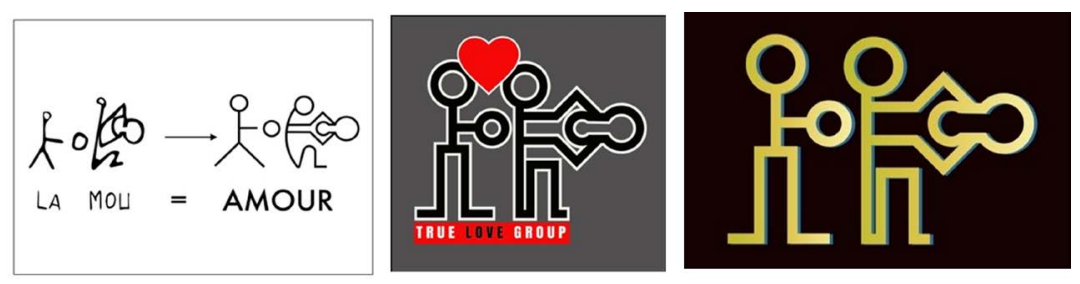

Figure 21. (From lelft to right). Poster created by auteur using expressing LOVE.
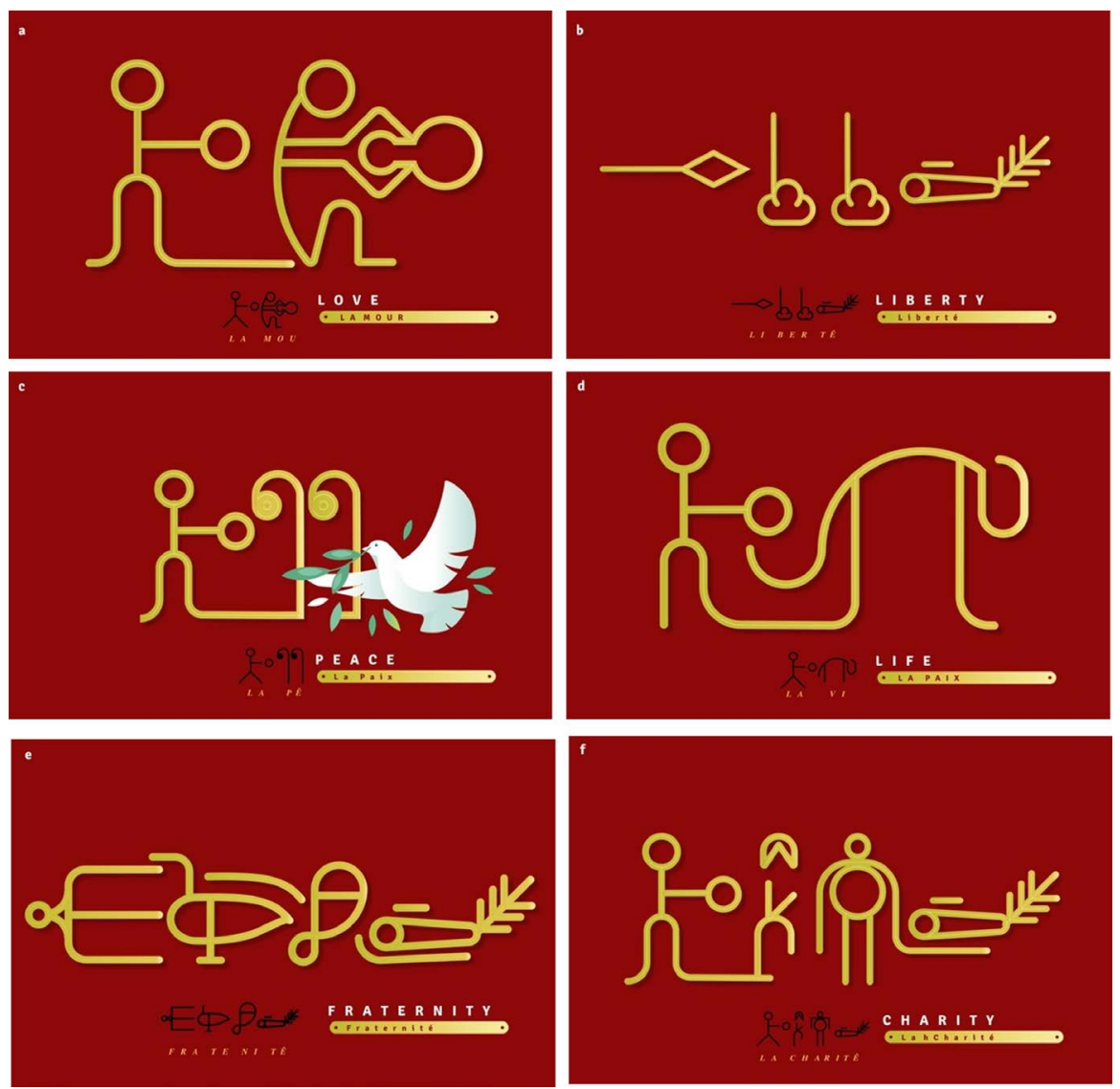

Figure 22. Series of auspicious logo realized from the Bété script using words:love, Freedom, Peace, Life, Brotherhood, Charity. 
characters and paragraphs. This can be facilitated by variation in text (or character) size, and by variation in type density and rhythm. We can therefore see that the layout will allow us to obtain a good result.

The use of Bété characters, as letters of visual communication in the design of books, will make it possible to popularize the Bété script throughout the world.

In book design, it is also possible to combine various characters, thus giving a sense of modernity and rhythm, as in some fashion magazines. In summary, in book design, Bété characters along with other design elements, the coordinated combinations, and arrangement of Bété characters themselves convey relevant information to the reader. It is, therefore, necessary that designers use many ways to improve and enrich content and form of the book (Figure 23 and Figure 24).

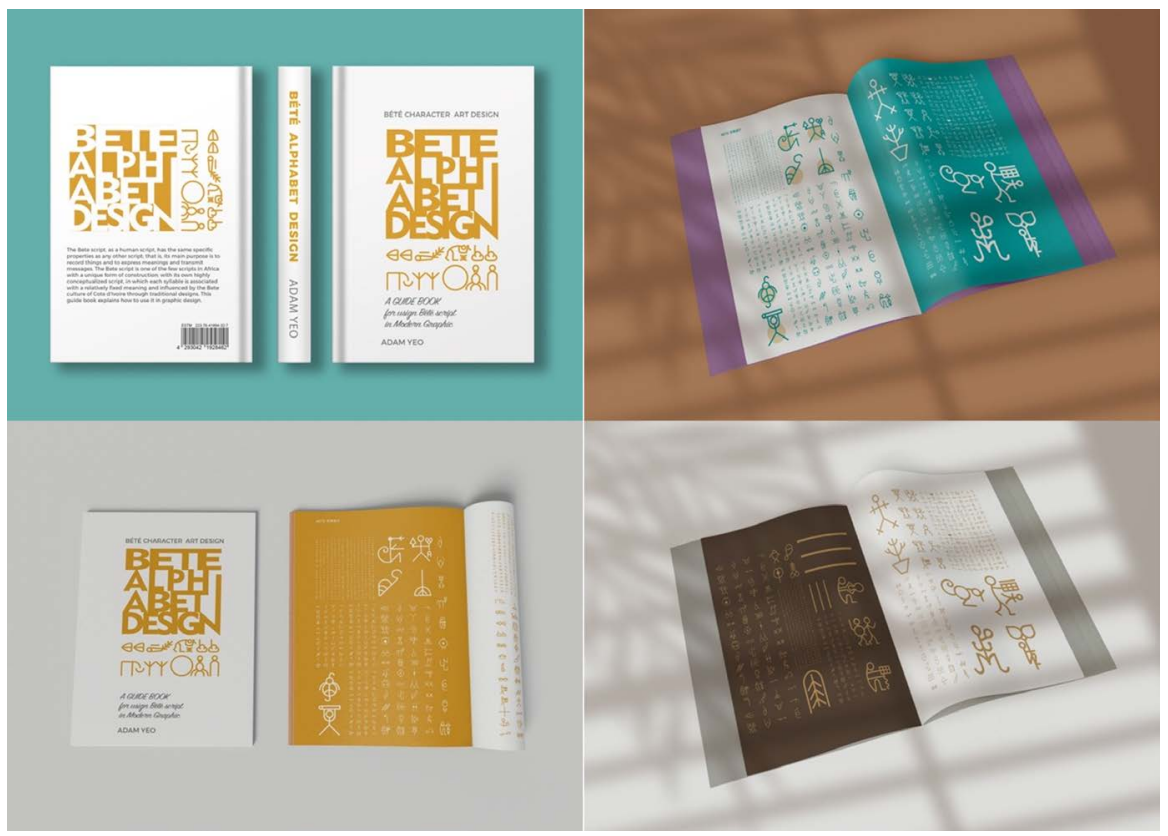

Figure 23. Book design using the Bété script.
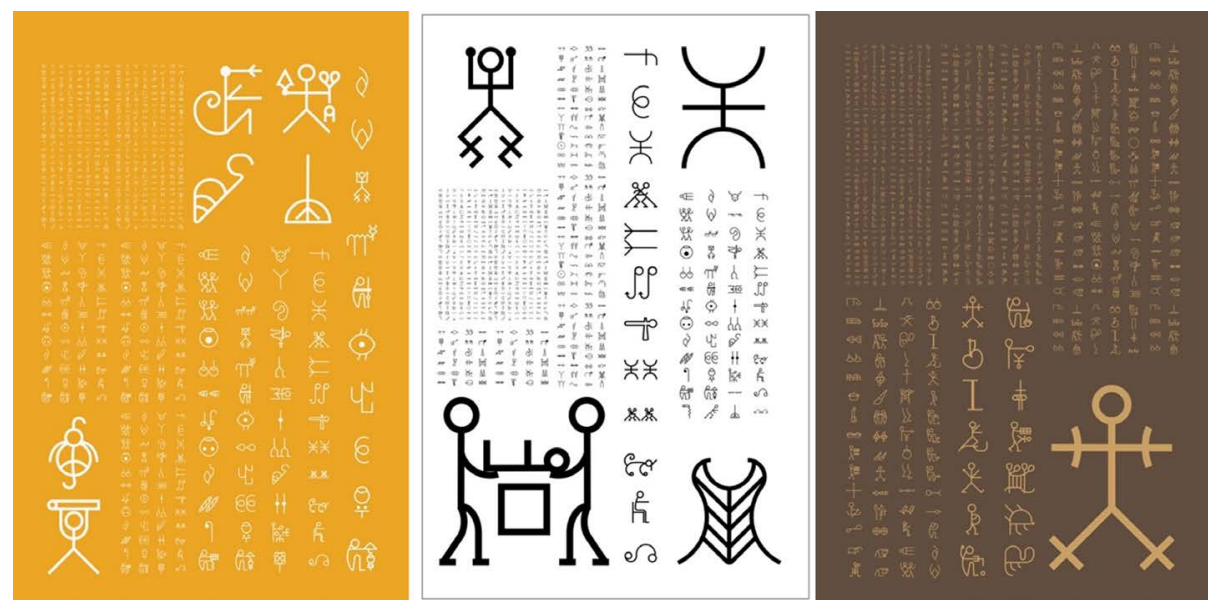

Figure 24. Book design using the Bété script. 


\section{Conclusion}

This article takes the Bété script as a design object. From the point of view of visual communication and font design, it studies the current Bété script and analyzes its morphological structure to find a method for its use in graphic design directions. Based on the observation that Béte script and the whole African script are less used in graphic design, because of the inexistence of theoretical and practical methods for their extension in modern graphic design. Therefore, this article tried to put forward research on the creative design of Bété script from a new method of font design to achieve a new form of Bété fonts, innovative. Through research in this paper, relevant conclusions are drawn:

1) A standardized font design method suitable for Bété font design is developed using the font analysis method. Using a scientific and rational grid to explore a standardized font of each letter of the Bété syllabary; secondly, through a mode of combination between the different characters or letters of the Bété script; The way of forming and arranging them, a new set of complete fonts of 448 (syllabary) was designed.

2) From the point of view of the creative application, by borrowing the font design methods; the metric design method, referring to the "six rules of Chinese calligraphy" and relying on the special characteristics of Béte script, the renovated Bete script has been applied in graphic design schemes, such as logos, posters, book design.

3) Thanks to the integration of methods of reflection adapted to the use of the Bete script, this article considers that the Béte script fulfills the possible conditions for its use in all directions of graphic design, making it a potential element of modern graphic design in the same way as Chinese, Latin, Arabic, Hebrew types... and participate in enriching the culture of international design by promoting the Bete script.

However, the design and use of script fonts that are not well known and less practiced such as the Bété script is not easy to promote and implement because of the small audience. However, we hope that this article will open the way and encourage designers to integrate more the Bété script into their design research.

\section{Conflicts of Interest}

The authors declare no conflicts of interest regarding the publication of this paper.

\section{References}

Bouabré, F. B. (1982). Ouest African Alphabet (The Bété). Ivory Coast.

Bouabré, F. B. (2013). Lettre de Frédéric Bruly Bouabré à Théodore Monod, datée du 19 novembre 1957, dans Frédéric Bruly Bouabré, L'Alphabet ouest-africain: Le bété. Paris: Éditions Xavier Barral.

Cédric, V. (2016). La prise du dessin par Bruly Bouabré ou le prophétisme retrouvé. Cahiers d'Études Africaines, 223, 517-538. 
https://doi.org/10.4000/etudesafricaines.18448

Chen, N. (2018). A Study in Chinese Characters. Wuhan: Hubei Art Publishing House.

Dalby, D. (1967). A Survey of the Indigenous Scripts of Liberia and Sierra Leone: Vai, Mende, Loma, Kpelle and Bassa. In M. Guthrie (Ed.), African Language Studies (pp. 1-51). London: School of Oriental and African Studies.

Dalby, D. (1968). The Indigenous Scripts of West Africa and Surinam: Their Inspiration and Design. African Language Studies, 9, 156-197.

Dalby, D. (1969). Further Indigenous Scripts of West Africa: Manding, Wolof, and Fula Alphabets and Yoruba Holy-Writing. African Language Studies, 10, 161-191.

Escudier, D. (2008). Naissance d'une Écriture: “L'Écriture Africaine” de Frédéric BRULY Bouabré. Académie d'Orléans Agriculture, Sciences, Belles-Lettres et Arts, 18, 61-108. http://www.lacado.fr/files/memoires-2008-61-108.pdf

Guim, L. (2015). Research on Chinese and Latin Typography For Multilingual Design [中 西合璧字体对于多语言设计的研究]. Beijing: University of Science and Technology Beijing Press.

Jaguar, L. E. (2011). Alts de l'Afrique. Paris: Les Editions du Jaguar.

Kreamer, C. M., Roberts, M. N., Harney, E., \& Purpura, A. (2007). Inscribing Meaning: Writing and Graphic Systems in African Art. African Arts, 40, 78-91. https://doi.org/10.1162/afar.2007.40.3.78

MAMCO (2006, Février 22). Geneve MAMCO. (The Jean Pigozzi Collection of African Art). Retrieved September 2018, from Bouabré, Frédéric Bruly, Connaissance du monde, 1977-2005. https://archive.mamco.ch/artistes_fichiers/B/bouabre.html

Meggs, P. B., \& Purvis, A. W. (2006). Meggs' History of Graphic Design (4th ed.). Hoboken, NJ: Wiley.

Michel, O. (1995) Worlds Envisioned: Alighiero e Boetti and Frédéric Bruly Bouabré. Third Text, 9, 95-97. https://doi.org/10.1080/09528829508576583

Yun, W. (2000). A Study of the Six Books of Sayings. Changchun: Jilin Literature and History Press. 